\title{
Fenologia de espécies nativas com potencial paisagístico
}

\section{Phenology of native species with landscaping potential}

\author{
Angeline Martini ${ }^{1}$; Daniela Biondi2 ${ }^{*}$; Antonio Carlos Batista ${ }^{3}$; Camila Maria Natal ${ }^{4}$
}

\section{Resumo}

O presente estudo visou determinar a fenologia de 10 espécies oriundas do ecossistema de Campos no estado do Paraná. São elas: Borreria suaveolens G. Mey.; Crotalaria hilariana Benth.; Cuphea calophylla Cham. \& Schltdl.; Desmodium adscendens (Sw) DC.; Desmodium incanum DC.; Hypericum connatum Lam.; Peltodon rugosus Tolmachev; Salvia lachnostachys Benth.; Sida macrodon DC.; Tibouchina gracilis (Bonpl.) Cogn.. O monitoramento de caráter qualitativo, realizado quinzenalmente, teve início no mês de janeiro de 2007. Foram avaliadas características reprodutivas e vegetativas. As variáveis meteorológicas relacionadas com a fenologia foram: temperatura do ar, umidade relativa, precipitação e fotoperíodo. Os resultados mostram que $80 \%$ das espécies apresentam término do período de floração entre os meses de abril e maio. Apenas Cuphea calophylla apresentou floração durante todo o tempo observado. Nos meses de maio e junho ocorreu a maior dispersão de sementes. As variáveis temperatura, fotoperíodo e precipitação apresentaram as melhores relações com as fenofases das plantas, com destaque para a temperatura.

Palavras-chave: Fenofases, floração, frutificação, ecossistema de Campos

\begin{abstract}
The aim of this work was to study the phenology of ten species that occur in the "Campos" ecosystem in Paraná state. They are: Borreria suaveolens G. Mey. ; Hilariana Crotalaria Benth. ; Cuphea calophylla Cham. \& Schltdl.; Desmodium adscendens (Sw) DC.; Desmodium incanum DC.; Hypericum connatum Lam. ; Peltodon rugosus Tolmachev; Salvia lachnostachys Benth; Been macrodon DC.; Tibouchina gracilis (Bonpl.) Cogn. The monitoring, by qualitative character, realized each fifteen days, had beginning in the month of January of 2007. It had been evaluated reproductive and vegetative characteristics. The meteorological variables that had been related with the phenology were: air temperature, relative humidity, precipitation and photoperiod. The results show that $80 \%$ of the species present ending of the period of budding between April and May. Cuphea calophylla was the only species that presented budding during all the observed time. The bighest dispersal of seeds occurred in May and June. Temperature, photoperiod and precipitation had been the variables that had shown better relationship with phenophases of the plants, especially the temperature.
\end{abstract}

Key words: Penophase, reproductive phases, vegetative period, Campos ecosystem

1 Acadêmica do Curso de Engenharia Florestal da Universidade Federal do Paraná/UFPR, Bolsista de Iniciação Científica - CNPq. E-mail: ange_martini@terra.com.br

2 Engenheira Florestal, Dra., Professora Associada II do Departamento de Ciências Florestais Universidade Federal do Paraná/ UFPR, Bolsista de Produtividade do CNPq. E-mail: dbiondi@ufpr.br

3 Engenheiro Florestal, Professor Associado II do Dr., Depto. de Ciências Florestais da Universidade Federal do Paraná / UFPR, Bolsista de Produtividade do CNPq. E-mail: batistaufpr@ufpr.br

${ }^{4}$ Acadêmica do Curso de Engenharia Florestal da Universidade Federal do Paraná/UFPR, Bolsista do PET-Floresta E-mail: mila natal@yahoo.com.br

* Autor para correspondência 


\section{Introdução}

O mercado brasileiro de plantas ornamentais desde sua implantação tem como base as espécies exóticas, devido tanto a questões culturais quanto a disponibilidade e facilidade de informações. Pouco se sabe sobre as espécies do ecossistema original nas áreas urbanas do país. A introdução destas no paisagismo é uma forma de valorizar e conservar a flora local que abriga espécies ainda desconhecidas pela população, mas que já se encontram em risco de extinção.

Segundo Fischer et al. (2007), a carência de pesquisas no Brasil na área de plantas nativas ornamentais causa a subutilização do potencial que a flora nacional oferece. Uma das grandes ameaças ao desaparecimento das espécies nativas é o processo de urbanização.

A cidade de Curitiba e arredores já foram cobertas por campos naturais, que atualmente, estão submetidos a uma densa pastagem, apresentando por isso uma vegetação profundamente alterada (KLEIN; HATSCHBACH, 1962).

De acordo com Veloso, Rangel Filho e Lima (1991), o ecossistema Campos é classificado como Estepe Gramíneo-Lenhosa. Esta paisagem uniforme é contrastada com a ocorrência de agrupamentos arbóreos marginais aos rios ou isolados sobre o campo, de formas e dimensões variáveis, sobressaindo a Araucaria angustifolia associada a vários grupos arbóreos (RODERJAN et al., 2002). Os capões de pinheiros, instalados sobre os campos, situam-se nas pequenas depressões de terreno, nos locais onde brotam fontes de água e em outros pontos cujo solo é mais favorável $(\mathrm{KOCH}$; CORRÊA, 2002).

Os Campos apresentam aspecto fisionômico típico com a predominância da cobertura herbácea (KLEIN; HATSCHBACH, 1970-1971). Segundo Roderjan et al. (2002), essa constituição essencialmente graminóide e de ocorrência sobre terrenos suaveondulados, compõe um elemento característico da paisagem dos planaltos do Sul do Brasil.
Gerar informações referentes ao desenvolvimento da planta em seu ambiente é uma das ferramentas básicas para se indicar o uso ornamental e as necessidades da mesma. Através da fenologia é possível determinar as fases da planta (fenofases) referentes à floração, frutificação e foliação.

Segundo Lieth ${ }^{5}$ citado por Morellato (1991), a fenologia é uma das mais importantes linhas de pesquisas e considerada um dos melhores parâmetros a ser utilizado para caracterizar ecossistemas. Ela pode ser definida como uma abordagem baseada no início e na duração de alterações visíveis no ciclo de vida das plantas correlacionadas com fatores climáticos (LARCHER, 2006). Ou ainda, segundo Fina e Ravelo ${ }^{6}$ citado por Bergamaschi (2004), fenologia é o ramo da Ecologia que estuda os fenômenos periódicos dos seres vivos e suas relações com as condições do ambiente, tais como temperatura, luz, umidade, etc.

A fenologia contribui para o entendimento da regeneraçãoe reprodução das plantas, da organização temporal dos recursos dentro das comunidades, das interações planta-animal e da evolução da história de vida dos animais que dependem de plantas para alimentação, como herbívoros, polinizadores e dispersores (MORELLATO, 1991; MORELLATO; LEITÃO-FILHO, 1992; MORELLATO; LEITÃOFILHO, 1996).

Análises fenológicas podem servir como referência nos estudos botânicos eecológicos, através do apoio a trabalhos que envolvam desde fisiologia de sementes até revisões taxonômicas, o que serve de base na construção de um plano de manejo e na elaboração de um projeto que vise à manutenção de espécies ameaçadas de extinção (SILVA; SANTOS, 2007). Segundo Mellinger e Richers (2005), este estudo visa fornecer parâmetros para a conservação e exploração racional, conciliando sustentabilidade com economicidade.

5 LIETH, H. Purpose of a phenology book. In: LIETH, H. (Ed.). Phenology and seasonality modeling, Berlin: Springer - Verlag, Berlin, 1974. p.3-19.

6 FINA, A. L.; RAVELO, A. C. Climatologia y fenologia agrícolas. Buenos Aires: Universitária, 1973. 281p. 
Para espécies comerciais ou consideradas criticamente ameaçadas, obter o conhecimento da fenologia é um passo importante para estabelecer as práticas adequadas de manejo (BEDÊ; MARTINS, 2008).

Biondi, Leal e Batista (2007) afirmam que o conhecimento das fases pela qual a planta passa pode servir tanto como base para a coleta de material fértil, como para pesquisas de reprodução de espécies visando à conservação de biomas e recuperação de áreas degradadas.

O comportamento das espécies está marcado pela ocorrência das fases fenológicas resultantes dos estímulos do clima, principalmente temperatura e precipitação (PRAUSE; ANGELONI, 2000). Costa (2002) afirma que estes estudos procuram examinar as relações entre os ciclos das plantas e as flutuações registradas em certos parâmetros ambientais, em especial na disponibilidade de água no solo (precipitação pluvial) ou na temperatura do ar. Explica também, que os fatores indutores de um determinado evento fenológico não são necessariamente as causas que selecionaram sua evolução. Mudanças fenológicas podem ser, por exemplo, uma resposta evolutiva às pressões exercidas por certos animais.

Para o paisagismo é de fundamental importância conhecer a época e a duração da floração, a característica mais apreciada pelos consumidores, assim como a época de dispersão de sementes, necessária para uma futura produção comercial da espécie. Tendo isto em vista, este trabalho tem como objetivo principal determinar o desenvolvimento fenológico de algumas espécies de Campos que possuem grande potencial paisagístico e relacionálas com fatores meterológicos.

\section{Material e métodos}

Descrição da Área de Estudo

O presente trabalho foi realizado no Campus III da Universidade Federal do Paraná, bairro Jardim
Botânico, Curitiba-PR. A Capital paranaense localiza-se no Primeiro Planalto a uma altitude média de 934,6 m acima do nível do mar (IPPUC, 2006) e situa-se a $25^{\circ} 43^{\prime}$ de latitude sul e $49^{\circ} 27^{\prime}$ de longitude oeste (INPE, 2008). Tendo-se por referência a classificação de Köppen, a cidade de Curitiba localiza-se em região climática do tipo $\mathrm{Cfb}$, com clima subtropical úmido, mesotérmico, sem estação seca, com verões frescos e invernos com geadas freqüentes e ocasionais precipitação de neve. Segundo o último estudo realizado pelo IPPUC entre os anos de 1998 e 2001, Curitiba apresentou temperatura média de $17,48^{\circ} \mathrm{C}$, precipitação média anual de $1571,28 \mathrm{~mm}$ e umidade média relativa do ar de 78,87\% (IPPUC, 2006).

Conforme a descrição de Roderjan et al. (2002), antes da ação antrópica, a vegetação original da cidade era constituída por Estepe GramíneoLenhosa (Campos), entremeada de agrupamentos arbóreos (com a presença de Araucárias), próximos a baixadas e riachos.

\section{Espécies Amostradas}

Foram selecionadas 10 espécies herbáceas (Figura 1) características da região e que apresentam grande potencial ornamental, segundo Natal, Biondi e Martini (2007). Estas foram herborizadas e identificadas no Museu do Jardim Botânico da Prefeitura Municipal de Curitiba. São elas: Crotalaria hilariana Benth. (Fabaceae); Salvia lachnostachys Benth. (Lamiaceae); Borreria suaveolens G. Mey. (Rubiaceae); Peltodon rugosus Tolmachev (Lamiaceae); Tibouchina gracilis (Bonpl.) Cogn. (Melastomataceae); Cuphea calophylla Cham. \& Schltdl. (Lythraceae); Sida macrodon DC. (Malvaceae); Hypericum connatum Lam. (Clusiaceae); Desmodium adscendens (Sw.) DC. (Fabaceae); Desmodium incanum DC. (Fabaceae). 

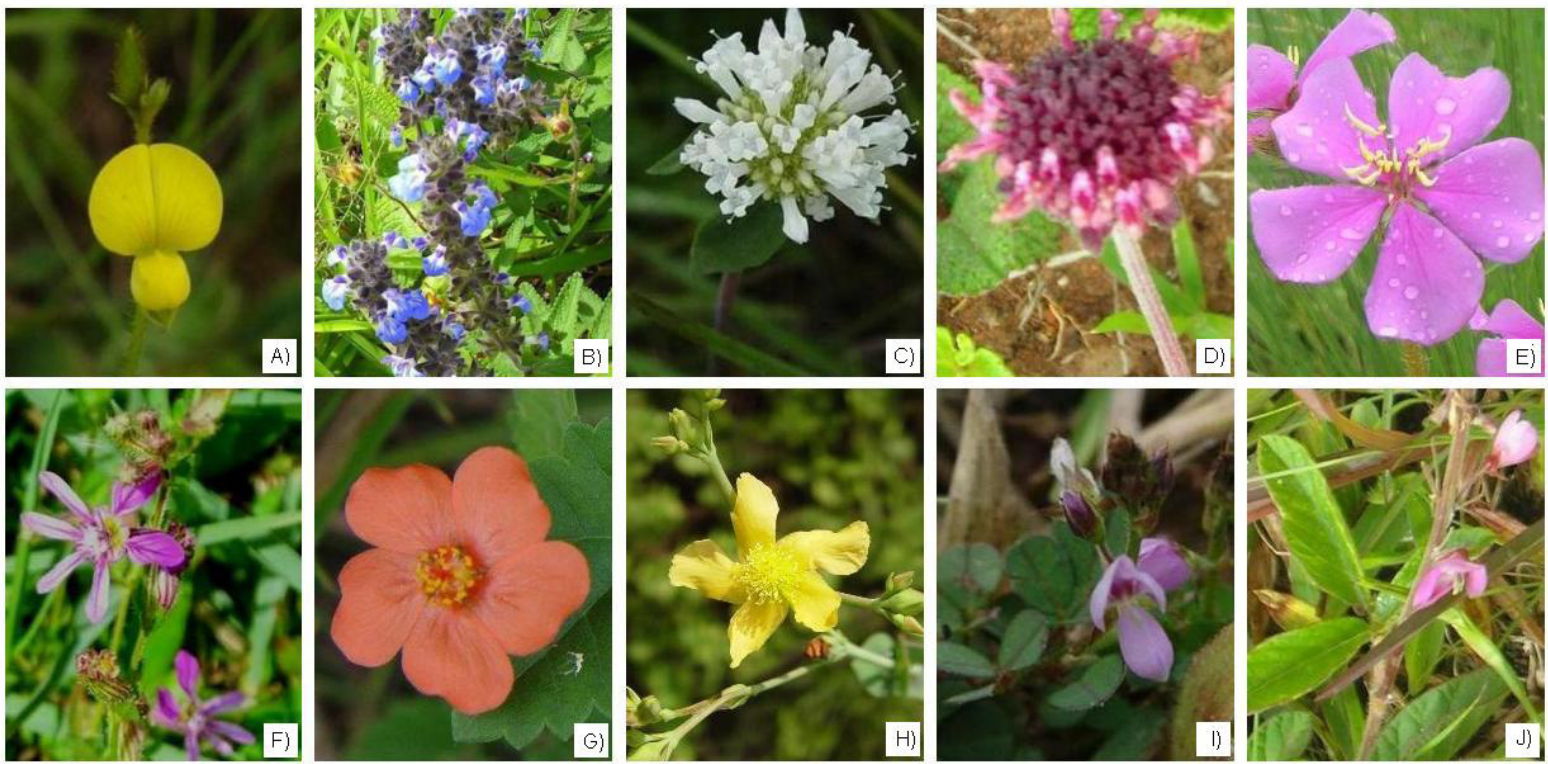

Figura 1. Espécies estudadas: A - Crotalaria hilariana; B - Salvia lachnostachys; C - Borreria suaveolens; D Peltodon rugosus; $\mathbf{E}$ - Tibouchina gracilis; $\mathbf{F}$ - Cuphea calophylla; $\mathbf{G}$ - Sida macrodon; $\mathbf{H}$ - Hypericum connatum; $\mathbf{I}$ - Desmodium adscendens; J - Desmodium incanum;

\section{Procedimentos Metodológicos}

O acompanhamento fenológico foi realizado de maneira qualitativa, ou seja, foi observada apenas a presença ou ausência da fenofase no indivíduo referente às características reprodutivas e vegetativas. As observações foram conduzidas quinzenalmente em três indivíduos de cada espécie entre janeiro de 2007 a abril de 2008 , isto porque o trabalho se iniciou em janeiro para cinco espécies e em abril para as demais. Neste período foi registrada a ocorrência das fenofases de florescimento (botões florais, floração adiantada, floração terminada), frutificação (frutos novos, frutos maduros, frutos caindo ou sementes dispersando), e perda e brotação das folhas (folhas novas, maioria de folhas novas, maioria de folhas velhas, desfolhada).

As fenofases das plantas foram correlacionadas com dados meteorológicos obtidos junto ao Instituto SIMEPAR. Estes dados, obtidos e processados quinzenalmente, foram: valores médios diários de temperatura $\left({ }^{\circ} \mathrm{C}\right)$, umidade relativa do ar $(\%)$ e os valores totais diários de precipitação $(\mathrm{mm})$ e fotoperíodo (h).

\section{Resultados e Discussão}

\section{Padrões Fenológicos das Espécies}

$\mathrm{Na}$ (Figura 2) são apresentadas as fenofases reprodutivas das espécies que tiveram seu acompanhamento fenológico iniciado no mês de janeiro e na (Figura 3) são apresentadas as fenofases reprodutivas das espécies que tiveram seu acompanhamento fenológico iniciado no mês de abril.

Observa-se nas duas figuras que a única espécie a apresentar fases de floração e frutificação durante todo o período observado foi a Cuphea calophylla. Todas as outras apresentaram distinção entre o período reprodutivo e vegetativo, onde $80 \%$ das espécies apresentam término do período de floração entre os meses de abril e maio (40\% em abril e $40 \%$ em maio), apenas Tibouchina gracilis encerra a floração no mês de março e, todas as espécies têm dispersão de sementes nos meses de maio e junho. 


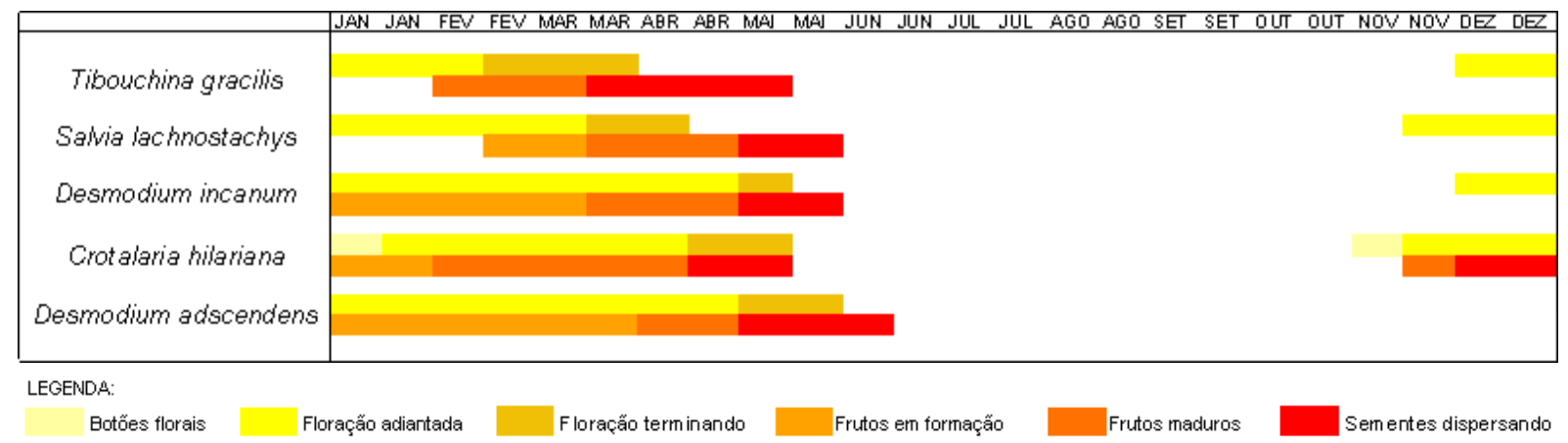

Figura 2. Fenofases reprodutivas das espécies selecionadas (monitoramento iniciado em janeiro)

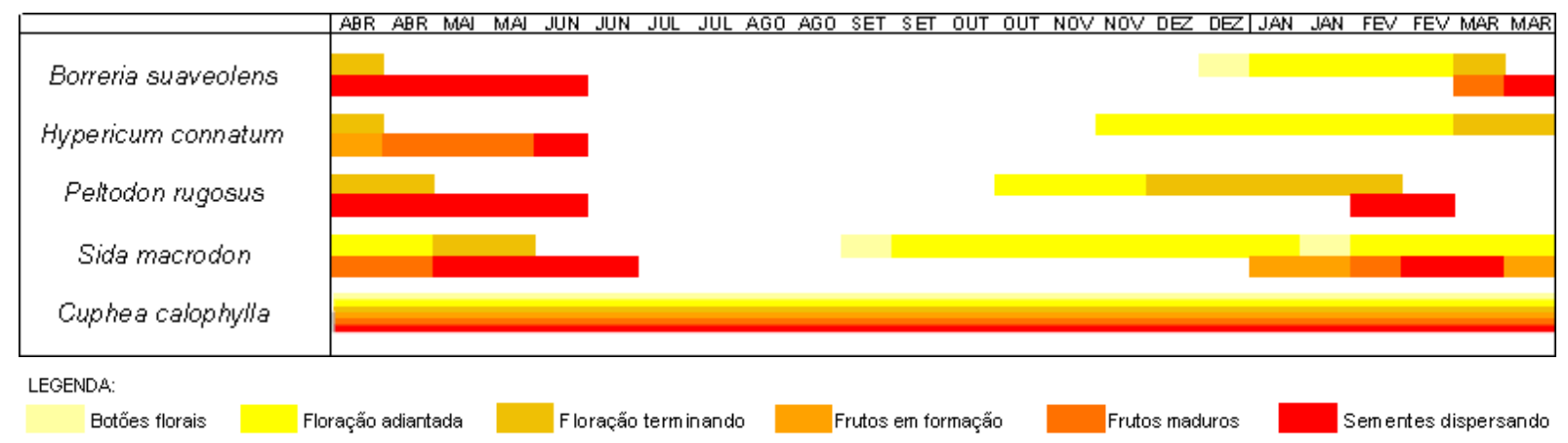

Figura 3. Fenofases reprodutivas das espécies selecionadas (monitoramento iniciado em abril)

As (Figuras 4 e 5) referem-se às fenofases vegetativas das espécies, com inicio do acompanhamento em janeiro e abril. Nota-se que com exceção da Cuphea calophylla, todas as espécies apresentam período de estagnação na produção de folhas, $30 \%$ apresentam período de estagnação de
2 a 3 meses, $40 \%$ entre 4 e 5 meses e $30 \%$ têm um período maior que 5 meses.

A descrição detalhada do acompanhamento fenológico de cada espécie e outras informações de importância para o paisagismo são apresentadas a seguir:

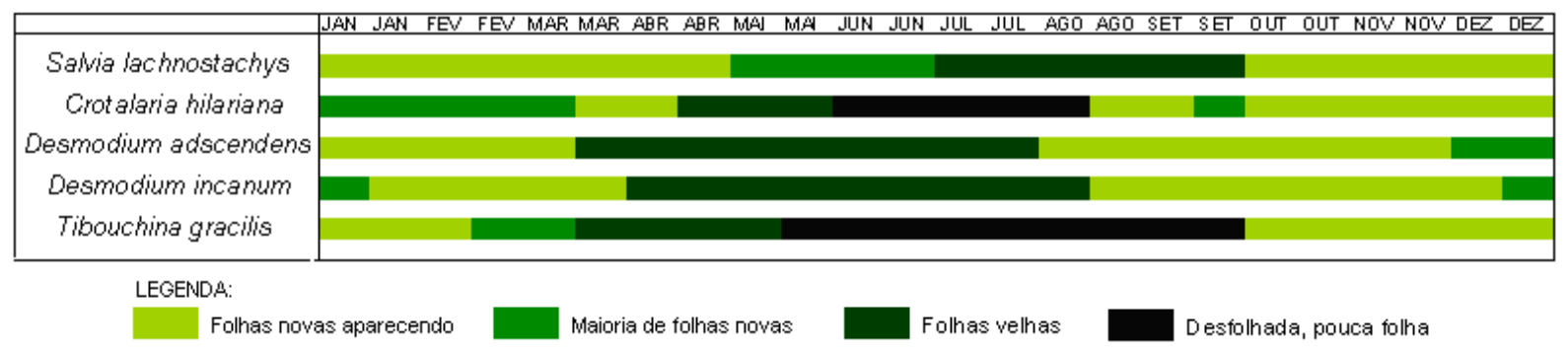

Figura 4. Fenofases vegetativas das espécies selecionadas (monitoramento iniciado em janeiro) 


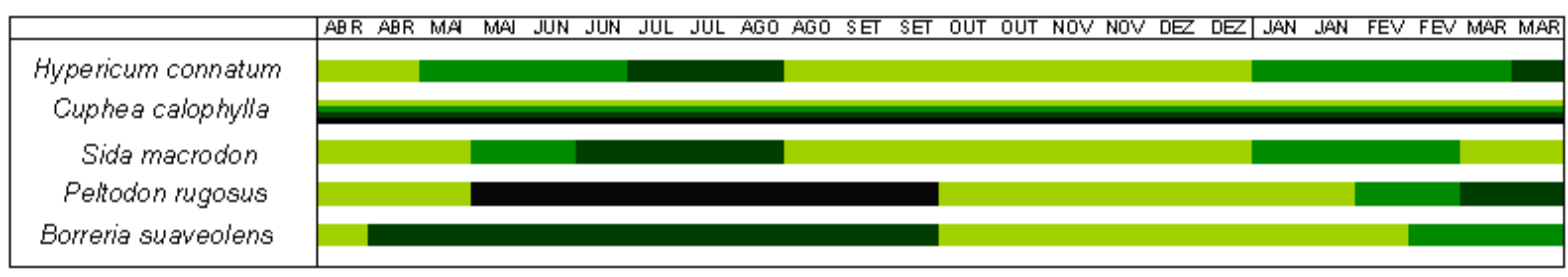

LEGENDA:

Folhas novas aparecendo $\square$ Maioria de folhas novas $\square$ Folhas velhas $\square$ Destolhada, pouca folha

Figura 5. Fenofases vegetativas das espécies (monitoramento iniciado em abril)

a) Borreria suaveolens - planta com flores brancas, altura média de $35 \mathrm{~cm}$, cultivada a pleno sol, alógama e não caducifólia. Apresenta período de floração de dezembro a abril (5 meses) e frutificação entre março e junho, com dispersão de sementes a partir da metade do mês de março à metade do mês de junho. Seu período de estagnação na produção de folhas ocorre de abril a setembro (6 meses).

b) Crotalaria hilariana - planta com flores amarelas, altura média de $18 \mathrm{~cm}$, cultivada a pleno sol, alógama e caducifólia. Apresenta período de floração de novembro a maio ( 7 meses) e a frutificação ocorre neste mesmo período, com dispersão de sementes em duas épocas, uma durante o mês de dezembro e outra entre março e abril. Seu período de estagnação na produção de folhas ocorre entre abril e agosto (5 meses).

c) Cuphea calophylla - planta com flores violetas, altura média de $20 \mathrm{~cm}$, cultivada a pleno sol e meiasombra, alógama e não caducifólia. Apresenta floração, frutificação e brotação durante todo o período observado (12 meses).

d) Desmodium adscendens - planta com flores lilás, altura média de $15 \mathrm{~cm}$, cultivada a pleno sol e meia-sombra, alógama e não caducifólia. Apresenta período de floração de janeiro a maio (5 meses) e frutificação entre janeiro e junho, com dispersão de sementes em maio até a metade do mês de junho. Seu período de estagnação na produção de folhas é de março a julho (5 meses).

e) Desmodium incanum - planta com flores violetas clara, altura média de $20 \mathrm{~cm}$, cultivada a pleno sol e meia-sombra, alógama e não caducifólia. Apresenta período de floração de dezembro a maio (6 meses) e frutificação entre janeiro e maio, com dispersão de sementes apenas no mês de maio. Seu período de estagnação na produção de folhas é de abril a agosto (5 meses).

f) Hypericum connatum - planta com flores amarelas, altura média de $45 \mathrm{~cm}$, cultivada a pleno sol, alógama e caducifólia. Apresenta período de floração de novembro a abril (6 meses) e frutificação entre abril e junho, com dispersão de sementes apenas na primeira quinzena de junho. Seu período de estagnação na produção de folhas é de julho a agosto (2 meses).

g) Peltodon rugosus - planta com flores violetas, altura média de $40 \mathrm{~cm}$, cultivada a pleno sol, alógama e caducifólia. Apresenta período de floração de outubro a fevereiro e posteriormente em abril (6 meses) e frutificação em março e entre abril e junho, com dispersão de sementes em todo esse período. Sua fase de estagnação na produção de folhas ocorre de maio a setembro (5 meses).

h) Salvia lachnostachys - planta com flores azuis, altura média de $25 \mathrm{~cm}$, cultivada a pleno sol, alógama e não caducifólia. Apresenta período de floração de novembro a abril (6 meses) e frutificação entre fevereiro e maio, com dispersão de sementes apenas no mês de maio. Seu período de estagnação na produção de folhas é de julho a setembro (3 meses).

i) Sida macrodon - planta com flores vermelhas, altura média de $20 \mathrm{~cm}$, cultivada a pleno sol e 
meia-sombra, alógama e não caducifólia apresenta período de floração de setembro a maio ( 9 meses) e frutificação entre janeiro e junho, com dispersão de sementes entre fevereiro e março e entre maio e junho. Seu período de estagnação na produção de folhas é de junho a agosto (3 meses).

j) Tibouchina gracilis - planta com flores violetas, altura média de $50 \mathrm{~cm}$, cultivada a pleno sol, alógama e caducifólia. Apresenta período de floração de dezembro a março (4 meses) e frutificação entre fevereiro e maio, com dispersão de sementes entre a segunda quinzena de março e a primeira quinzena de maio. Seu período de estagnação na produção de folhas é de março a setembro (7 meses).

É importante ressaltar que a única espécie a apresentar fases de floração e frutificação durante todo o período de estudo foi a Cuphea calophylla, característica considerada fundamental para o paisagismo, além de não apresentar fase de dessecamento. Todas as outras apresentaram distinção entre o período reprodutivo e vegetativo.

Outra espécie muito promissora foi Sida macrodon, que apenas no período de inverno não apresentou flores, ou seja, esteve em fase de floração durante nove meses do ano.

Hypericum connatum apresentou um bom período de floração (6 meses), não produz folhas por apenas dois meses e não tem fase de dessecamento, ressalta-se apenas o curto espaço de tempo para a dispersão de sementes. Foi observada tal fase apenas durante a primeira quinzena do mês de junho, fato que exige atenção para os casos em que se deseja a produção da espécie de maneira sexuada.

Borreria suaveolens, Desmodium adscendens e Tibouchina gracilis apresentaram períodos curtos de floração e longos períodos de estagnação da produção de folhas, características menos relevantes, Tibouchina gracilis permanece durante quatro meses na fase de floração, sete meses na fase de estagnação da produção de folhas e ainda um longo período de dessecamento.

\section{Relação das Fenofases com o Clima}

$\mathrm{Na}$ (Figura 6) é apresentado o comportamento dos elementos meteorológicos distribuídos trimestralmente entre janeiro de 2007 e abril de 2008, assim como a distribuição das fenofases das plantas. Observa-se que a temperatura média, a precipitação e a umidade relativa do ar tiveram seus mínimos valores no trimestre julhosetembro/2007, e os máximos valores no trimestre janeiro-março/2007 para temperatura e precipitação e janeiro-março/2008 para a umidade relativa do ar. Já o fotoperíodo alcança o seu mínimo entre o trimestre abril-junho e o máximo em outubrodezembro/2007.

A porcentagem de espécies em floração, frutificação e brotação é menor no trimestre julhosetembro (13,3\%; 10,0\% e 36,7\%, respectivamente), mesmo trimestre quando ocorrem os menores valores de temperaturas médias $\left(16,0{ }^{\circ} \mathrm{C}\right)$, precipitação (145,0 mm) e umidade relativa $(76,1 \%)$. No trimestre janeiro-março de 2007 foi a época que ocorreu o maior número de espécies em floração (100\%) e frutificação $(83,3 \%)$. Na mesma época ocorre a maior quantidade de precipitação $(459,0 \mathrm{~mm})$ e apresenta maiores temperatura médias $\left(21,9{ }^{\circ} \mathrm{C}\right)$. O período de maior brotação foi outubro-dezembro (100\%), mesmo trimestre com maior fotoperíodo (13,3 h).

No período estudado observou-se uma grande interação das fenofases da planta com a variável meteorológica temperatura média, e um pouco menos expressiva, com o fotoperíodo e a precipitação. Segundo Larcher (2006), o início e a duração das distintas fases de desenvolvimento da planta varia de ano para ano, dependendo das condições climáticas.

Observando-se a (Figura 6) é possível notar que a baixa porcentagem de espécies em floração, frutificação e brotação ocorre no período em que se observa os menores valores de temperatura média, precipitação e umidade relativa. Por outro lado, a maior quantidade de floração e frutificação ocorre na 

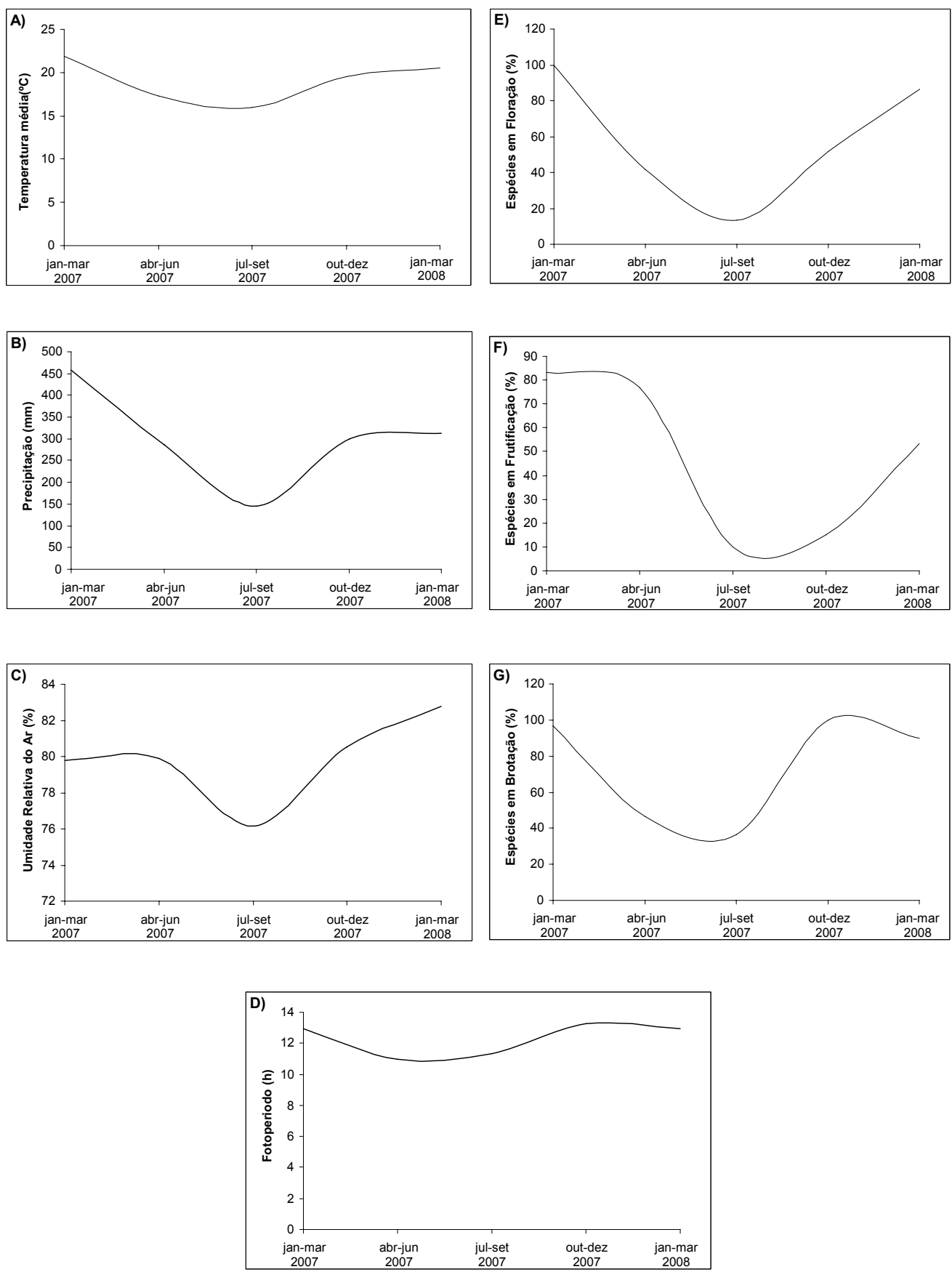

Figura 6. Comportamento das variáveis meteorológicas: Temperatura (A), Precipitação (B), Umidade Relativa do Ar (C), Fotoperíodo (D) e as fenofases: Floração (E), Frutificação (F), Brotação (G) por trimestre nos anos 2007 e 2008 
época de maior temperatura média e quantidade de precipitação, assim como o alto valor de brotações ocorre na época de maior fotoperíodo.

Alguns autores já demonstraram a relação entre as fenofases da planta e as variáveis meteorológicas fotoperíodo e temperatura média. Larcher (2006) afirma que não é uma tarefa fácil avaliar os fatores climáticos responsáveis pelo desencadeamento dos fenômenos fenológicos, pois o impulso efetivo, como, por exemplo, a passagem de um limite de temperatura, é modificado por um grande número de condições internas e externas. Segundo Castellani, Caus e Vieira (1999), as fases reprodutivas, ao contrário das fases vegetativas, parecem ser sempre estimuladas pela maior exposição solar e pelo aumento de temperatura, sem excesso de umidade no solo. Karam et al. (2002), estudaram a fenologia de quatro espécies de Senecio na região sul do Rio Grande do Sul e perceberam que em todas as áreas de observação as fases reprodutivas foram mais expressivas quando a temperatura e o fotoperíodo foram maiores. $\mathrm{O}$ mesmo resultado foi encontrado por Biondi, Leal e Batista (2007), que estudaram a fenologia do florescimento e frutificação de espécies nativas dos Campos.

Os resultados obtidos nesta pesquisa estão de acordo com Larcher (2006), que afirma que nas regiões dos subtrópicos com estações secas e chuvosas, as fenofases estão relacionadas às alterações periódicas de disponibilidade de água, onde a estação chuvosa representa o principal período de crescimento e na estação seca, as gramíneas e as herbáceas são dessecadas.

Ressalta-se que os resultados obtidos em relação às características fenológicas e às variáveis meteorológicas referem-se apenas ao período e ao local de estudo. Recomenda-se assim, a continuação do estudo em períodos mais longos e em outros locais da cidade para poder confirmar tais resultados.

\section{Conclusão}

Cuphea calophylla apresentou as fases de floração e frutificação durante todo o período observado e Sida macrodon apresentou seu período de floração interrompido apenas durante o inverno. Já Hypericum connatum destaca-se por apresentar fase vegetativa longa, além dos seis meses de floração.

As variáveis meteorológicas analisadas apresentaram relações significativas com as fenofases das plantas estudadas, principalmente para a temperatura média, que mostrou relação com todas as características observadas. Destaca-se também a relação com o fotoperíodo e a precipitação.

\section{Referências}

BEDÊ, L. C.; MARTINS, R. P. Fenologia de Syngonanthus elegans var. elanatus no parque Estadual do Rio Preto, Município de São Gonçalo do Rio Preto, MG. In: SEMANA DA PÓS-GRADUAÇÃO DA UFMG, 3., 2002. Belo Horizonte. Anais Eletrônicos... Belo Horizonte: UFMG, 2002. Disponível em: $<$ http://www. ufmg.br/prpg/dow_anais/cien_biologicas/ecologia_3/ lucioc_1.doc>. Acesso em: 20 jun. 2008.

BERGAMASCHI, H. Fenologia, 2004. Material didático da disciplina de relação clima-planta da faculdade de agronomia da UFRGS. Disponível em: http://www.ufrgs. br/agropfagrom/disciplinas/502/fenolog.doc.. Acesso em: 10 ago. 2008.

BIONDI, D.; LEAL, L; BATISTA, A. Fenologia do florescimento e frutificação de espécies nativas dos Campos. Acta Scientiarum. Biological Sciences, Maringá, v. 29, n. 3, p. 269-276, 2007.

CASTELLANI, T. T.; CAUS, C. A.; VIEIRA, S. Fenologia de uma comunidade de duna frontal no sul do Brasil. Acta Botanica Brasilica, São Paulo, v. 13, n. 1, p. 99-114, 1999.

COSTA, F. A. P. L. Fenologia de árvores tropicais. La insignia. 2002. Disponível em: <http://www.lainsignia. org/2002/ diciembre/dial_005.htm..>. Acesso em: 12 ago. 2008 .

FISCHER, S. Z.; STUMPF, E. R. T.; HEIDEN, G.; BARBIERI, R. L.; WASUM, R. A. Plantas da flora brasileira no mercado internacional de floricultura. Revista Brasileira de Biociências, Porto Alegre, v. 5, p. 510-512, 2007. Suplemento 1. 
INSTITUTO NACIONAL DE PESQUISAS ESPACIAIS -INPE. Meteorologia. Disponível em: <http://tempo. cptec.inpe.br:8080/prevnum/buscaMeteo.jsp?action=1\& modelo $=$ Eta $20 \&$ cidade $=$ curitiba\# $>$. Acesso em: 21 jul. 2008.

INSTITUTO DE PESQUISA E PLANEJAMENTO URBANO DE CURITIBA - IPPUC. Curitiba em dados 2006. Disponível em: <http://ippucnet.ippuc. org.br/Bancodedados/Curitibaemdados/anexos/2001 Características\%20do\%20Relevo\%20de\%20Curitiba.pd f>. Acesso em: 13 jun. 2008.

KARAM, F. S. C.; MENDEZ, M.C.; JARENKOW, J. A.; RIET-CORREA, F. Fenologia de quatro espécies tóxicas de Senecio (Ateraceae) na região Sul do Rio Grande do Sul. Pesquisa Veterinária Brasileira, Rio de Janeiro, v. 22, n. 1, p. 33-39, 2002.

KLEIN, R. M.; HATSCHBACH, G. Fitofisionomia e notas sobre a vegetação para acompanhar a planta fitogeográfica do município de Curitiba e arredores (Paraná). Boletim da Universidade do Paraná. Geografia Física. Curitiba, n. 4, 29 p. 1962.

Fitofisionomia e notas complementares sobre o mapa fitogeográfico de quero-quero (Paraná). Boletim Paranaense de Geociências, Curitiba, n. 28/29, 19701971.

KOCH, Z.; CORRÊA, M. C. Araucária a floresta do Brasil Meridional. Curitiba: Olhar Brasileiro. 2002.

LARCHER, W. Ecologia vegetal. São Carlos: Rima, 2006.

MELLINGER, L. L.; RICHERS, B. T. Fenologia de espéciesoleaginosasnaRDSAmaña(AM)-dadosparciais. 2005. Disponível em: <http:/www.mamiraua.org.br/ arq/Mellinger\&Richers-FenologiaOleaginosasAmanaSAPII.pdf $>$. Acesso em: 12 jul. 2008.

MORELLATO, L. P. C. Fenologia de árvores, arbustos e lianas em uma floresta semi-decidua no sudeste do
Brasil. Campinas, 1991, 176 f. Tese (Doutorado em Biologia) - Instituto de Biologia, Universidade Estadual de Campinas.

MORELlato, L. P. C.; LEITÃO-FILHO, H. F. Padrões de frutificação e dispersão na Serra do Japi. In: MORELLATO, L. P. C. (Org.). História natural da serra do japi: ecologia e preservação de uma área florestal no Sudeste do Brasil. Campinas: Unicamp/Fapesp, 1992, p. 112-140.

MORELlatO, L. P. C.; LEITÃO-FILHO, H. F. Reproductive phenology of climbers in a Southeasthern Brazilian forest. Biotropica, Lawrence, v. 28, n. 2, p. 180-191, 1996.

NATAL, C. M.; BIONDI, D.; MARTINI, A. Levantamento exploratório de espécies nativas com potencial ornamental. In: EVENTO DE INICIAÇÃO CIENTÍFICA, 15., 2007, Curitiba. Resumos... Curitiba: Próreitoria de Pós-Graduação UFPR, 2007. p. 34.

PRAUSE, J.; ANGELONI, P. Fenología de especies forestales nativas: abscisión de hojas. Universidad Nacional del Nordeste: Comunicaciones Científicas y Tecnológicas. 2000. Disponível em: < http://www.unne. edu.ar/Web/cyt/cyt/2000/5_agrarias/a_pdf/a_058.pdf >. Acesso em: 05 ago. 2008.

RODERJAN, C. V.; GALVÃO, F.; KUNIYOSHI, Y. S.; HATSCHBACH, G. G. As unidades fitogeográficas do Estado do Paraná. Ciência \& Ambiente, Santa Maria, v. 24, p. 75-92, 2002.

SILVA, C. B. M. C.; SANTOS, D. L. Fenologia reprodutiva de Melocactus conoideus Buin. \& Bred.: espécie endêmica do município de Vitória da Conquista, Bahia Brasil. Revista Brasileira de Biociências, Porto Alegre, v. 5, p. 1095-1097, 2007. Suplemento 2.

VELOSO, H. P., RANGEL FILHO, A. L., LIMA, J. C. A. Classificação da vegetação brasileira adaptada a um sistema universal. Rio de Janeiro: IBGE, 1991. 